\title{
Correction to: A novel hybrid MCDM approach to evaluate ports' dredging project criteria based on intuitionistic fuzzy DEMATEL and GOWPA
}

\section{Saeed Khorram ${ }^{1}$ (D) Mohammad Ali Khaleghi $^{1}$}

Published online: 17 June 2020

C) World Maritime University 2020

\section{Correction to: WMU J Marit Affairs 19, 95-124 (2020) https://doi.org/10.1007/s13437-018-0148-1}

The family name of the co-author of this article was misspelled. The correct name is Mohammad Ali Khaleghi.

The correct citation of this article should therefore be as follows:

Khorram, S., Khaleghi, M.A. A novel hybrid MCDM approach to evaluate ports' dredging project criteria based on intuitionistic fuzzy DEMATEL and GOWPA. WMU J Marit Affairs 19, 95-124 (2020)

Sadly, this mistake remained unnoticed.

The publisher apologizes for this mistake.

Publisher's note Springer Nature remains neutral with regard to jurisdictional claims in published maps and institutional affiliations.

The online version of the original article can be found at https://doi.org/10.1007/s13437-018-0148-1

\section{Saeed Khorram}

saeedkhorram@gmail.com

$\triangle$ Mohammad Ali Khaleghi

1 Department of Civil Engineering, Marvdasht Branch, Islamic Azad University, Marvdasht, Iran 